\title{
Model Predictive Control System Design for Boiler Turbine Process
}

\author{
Sandeep Kumar Sunori*, Pradeep Kumar Juneja**, Anamika Bhatia Jain*** \\ * Department of Electronics and Communication Engineering, Graphic Era Hill University, Bhimtal Campus, India \\ **School of Electronics, Graphic Era University, Dehradun, India \\ ***Department of Electronics and Communication, Dehradun, India
}

\begin{tabular}{l} 
Article Info \\
\hline Article history: \\
Received Feb 12, 2015 \\
Revised Jun 23, 2015 \\
Accepted Jul 10, 2015 \\
\hline Keyword: \\
Boiler turbine \\
Model predictive control \\
Multivariable process \\
Nonlinear process \\
Prediction horizon
\end{tabular}

\begin{abstract}
MPC is a computer based technique that requires the process model to anticipate the future outputs of that process. An optimal control action is taken by MPC based on this prediction. The MPC is so popular since its control performance has been reported to be best among other conventional techniques to control the multivariable dynamical plants with various inputs and outputs constraints. In the present work the control of boiler turbine process with three manipulated variables namely fuel flow valve position, steam control valve position and feed water flow valve position and three controlled variables namely drum pressure, output power and drum water level deviation has been attempted using MPC technique. Boiler turbine process is very complex and nonlinear multivariable process. A linearized model obtained using Taylor series expansion around operating point has been used.
\end{abstract}

Copyright (c) 2015 Institute of Advanced Engineering and Science. All rights reserved.

\section{Corresponding Author:}

Sandeep Kumar Sunori,

Departement of Electronics and Communication Engineering,

Graphic Era Hill University,

Sattal Road, PO: Bhowali, Bhimtal, Nainital (Uttarakhand), India

Email: sandeepsunori@gmail.com

\section{INTRODUCTION}

In boiler turbines fluctuation in the drum level is the big problem as the steam flow is directly proportional to power generation. In case the drum level goes down the lower threshold, the overheating inside the boiler may result in cracking of water tubes. On the other hand if the level goes up the desired upper threshold, the dry steam flowing to turbine may carry some water particles which may damage the turbine blades [1]. So the maintenance of the water level is the crucial task for safe operation of the turbine. The other parameters to be controlled are the drum pressure and the ultimate objective is to meet the load demand of electric power.

The MPC calculates an objective function [2] based on the prediction of the output samples up to a fixed prediction horizon and then determines the discrete moves of the input manipulated variables in such a way that the objective function is minimized. The MPC strategy is elaborated in figure1.

The MPC takes control actions at regularly spaced intervals which are called control intervals. As shown in figure1, the controller predicts the output values at sampling instant t. After having completed the prediction calculations it sends move $u(t)$ to the plant. The plant then operates with this constant input until the next sampling instant. At this sampling instant $t+1$, the controller again does prediction over prediction horizon in the same way and again determines the new optimal control moves over the control horizon and this cycle repeats indefinitely. Thus we see that both prediction and control horizons are receding. 


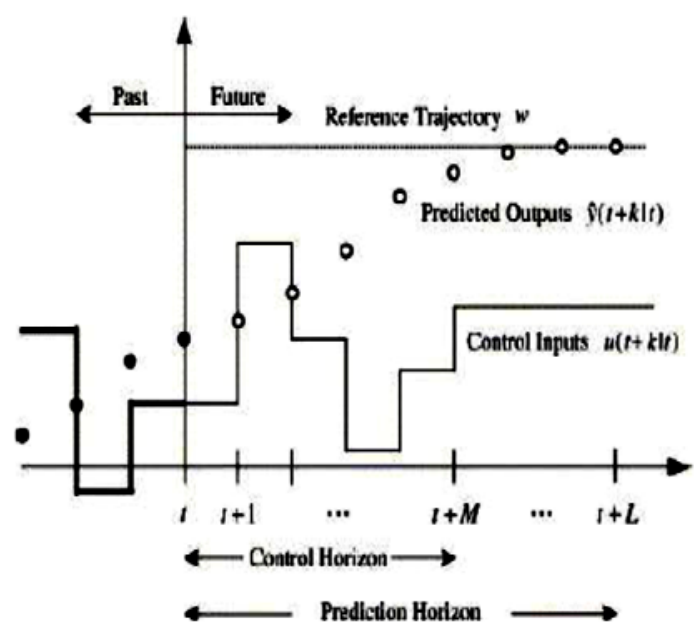

Figure 1. MPC strategy [3]

T. Rajkumar et al. [3] used wide open control strategy with 3 element control system to provide tight control the drum water level in boiler turbine. Three elements indicate 3 variables namely steam flow, feed water flow and drum water level which collectively has effect on feed water valve position. Drum Level Control Algorithm was implemented in the Advanced Adaptive PID Controller Block in the FCP270 Field Control Processor.

Quicker response and little overshoot was observed in the response of speed controller for steam turbine using MPC technique as compared to conventional PID controller and fuzzy controller [4].Omar shahin et al. observed robustness and satisfactory performance of the boiler turbine system employing adaptive wavelet neural network. Discrete Lyapunov stability theorem was used here to determine the learning rates [5].

Speed control of gas turbine system was proved to be outstanding with adaptive fuzzy PID controllers as compared to conventional controllers [6].

Linearization of a non linear model of boiler turbine plant about a suitable operating point was presented in the work done by Wen Tan and Fang Fang et al.[7].

Pradeep Kumar Juneja et al. discovered that if the ratio of control horizon to prediction horizon of an MPC controller remains same than its performance almost remains same for a given process [8].

Pang-chia Chen and Jeff S.Shamma reported gain scheduled $\mathrm{l}^{1}$ optimal control for regulating the drum water level in boiler turbines and obtaining the desired output power level [9].

A new coordinated control strategy(CCS) has been proposed for control of boiler turbine system which is executed in two levels namely the basic level in which conventional PID controllers are used to do fundamental control action and the high level in which the decoupling between two control loops is done. They also used a special class of fuzzy inference system to accomplish self tuning [10].

A multi input single output MPC has been developed for a bioreactor plant and its performance was compared with that of PID and fuzzy PID controllers [11].Fateme Pirouzmand proposed a robust MPC for three degree freedom satellite systems and the compensation of moment of inertia uncertainty and external disturbance was accomplished effectively by this technique [12].

\section{MPC CONTROLLER DESIGN}

The linearized state space model of the considered boiler turbine process with manipulated variables as fuel flow valve position $\left(\mathrm{u}_{1}\right)$, steam flow valve position $\left(\mathrm{u}_{2}\right)$ and feed water flow valve $\left(\mathrm{u}_{3}\right)$ and controlled variables as drum pressure $\left(\mathrm{y}_{1}\right)$ in $\mathrm{kg} / \mathrm{sq} . \mathrm{cm}$, output power $\left(\mathrm{y}_{2}\right)$ in $\mathrm{MW}$ and drum water level deviation $\left(\mathrm{y}_{3}\right)$ in meters with state variables as drum steam pressure $\left(\mathrm{x}_{1}\right)$ in $\mathrm{kg} / \mathrm{sq} . \mathrm{cm}$,electric power $\left(\mathrm{x}_{2}\right)$ in $\mathrm{MW}$ and steam water fluid density $\left(\mathrm{x}_{3}\right)$ in $\mathrm{kg} /$ cubic meter is represented by equations (1),(2) and (3) [13] . 


$$
\begin{aligned}
& {\left[\begin{array}{l}
\frac{d x_{1}}{d t} \\
\frac{d x_{2}}{d t} \\
\frac{d x_{3}}{d t}
\end{array}\right]=\mathrm{A}\left[\begin{array}{l}
x_{1} \\
x_{2} \\
x_{3}
\end{array}\right]+\mathrm{B}\left[\begin{array}{l}
u_{1} \\
u_{2} \\
u_{3}
\end{array}\right]} \\
& {\left[\begin{array}{l}
y_{1} \\
y_{2} \\
y_{3}
\end{array}\right]=\mathrm{C}\left[\begin{array}{l}
x_{1} \\
x_{2} \\
x_{3}
\end{array}\right]+\mathrm{D}\left[\begin{array}{l}
u_{1} \\
u_{2} \\
u_{3}
\end{array}\right]} \\
& \mathrm{A}=\left[\begin{array}{ccc}
-0.002854 & 0 & 0 \\
0.083152 & -0.1 & 0 \\
-0.007842 & 0 & 0
\end{array}\right] \\
& \mathrm{B}=\left[\begin{array}{ccc}
0.9 & -0.374591 & -0.15 \\
0 & 15.191754 & 0 \\
0 & -0.148126 & 1.658824
\end{array}\right] \\
& \mathrm{C}=\left[\begin{array}{ccc}
1 & 0 & 0 \\
0 & 1 & 0 \\
0.007566 & 0 & 0.004257
\end{array}\right] \\
& \mathrm{D}=\left[\begin{array}{ccc}
0 & 0 & 0 \\
0 & 0 & 0.014
\end{array}\right]
\end{aligned}
$$

Now this plant is to be controlled by an MPC controller with set points for controlled variables $\mathrm{y}_{1}, \mathrm{y}_{2}$ and $\mathrm{y}_{3}$ equal to $120 \mathrm{~kg} / \mathrm{sq} . \mathrm{cm}, 120 \mathrm{MW}$ and zero meters respectively. The 3 manipulated variables $\mathrm{u}_{1}$, $\mathrm{u}_{2}$ and $\mathrm{u}_{3}$ have a value over interval $[0,1]$. The MPC tuning parameters for the controller design are specified in table 1 as follows.

Table 1. Tuning parameters of MPC

\begin{tabular}{ll}
\hline Tuning Parameter & Value \\
\hline $\begin{array}{l}\text { Control interval(seconds) } \\
\text { (sampling interval) }\end{array}$ & 1.0 \\
Prediction horizon & 10 \\
Control horizon & 3 \\
Rate weight for inputs & 0.1 \\
Weight for drum presure & 1 \\
Weight for power output & 1 \\
Weight for water level & 0 \\
deviation & \\
Duration(seconds) & 30 \\
Robustness & 0.8 \\
\hline
\end{tabular}

\section{CONTROLLER PERFORMANCE}

With the tuning parameters specified in table 1 and the following setpoints,

Drum pressure: $120 \mathrm{~kg} / \mathrm{sq} . \mathrm{cm}$

Output Power: 120 MW

Water level deviation: zero

The setpoint tracking responses of the MPC controller is depicted in figure 2 showing that the performance of MPC is excellent with very good transient and steady state responses. 


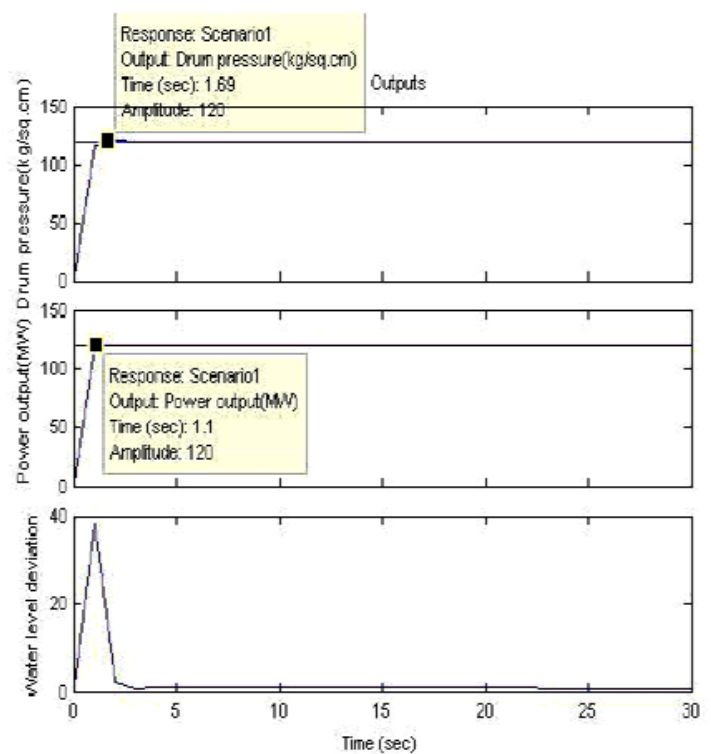

Figure 2. Set point response of MPC

\section{EFFECT OF VARIATION IN CONTROL HORIZON}

In this section, the consequences of varying MPC control horizon value will be investigated. The following plots in Figure 3 and 4 depict the set point tracking response of MPC with control horizon (CH) equal to 1,2 and 5 respectively keeping prediction horizon fixed at 10 [12].

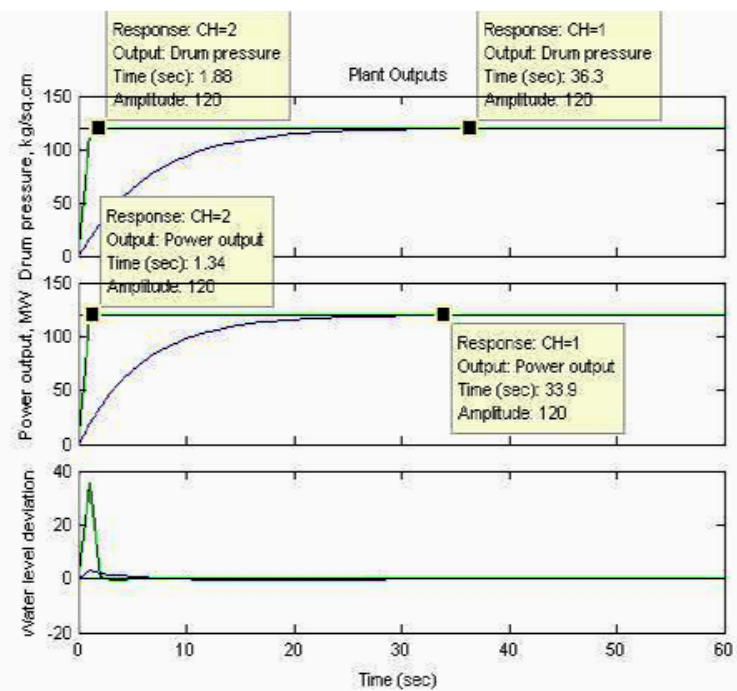

Figure 3. Set point responses with control horizon (CH) value of 1 and 2 


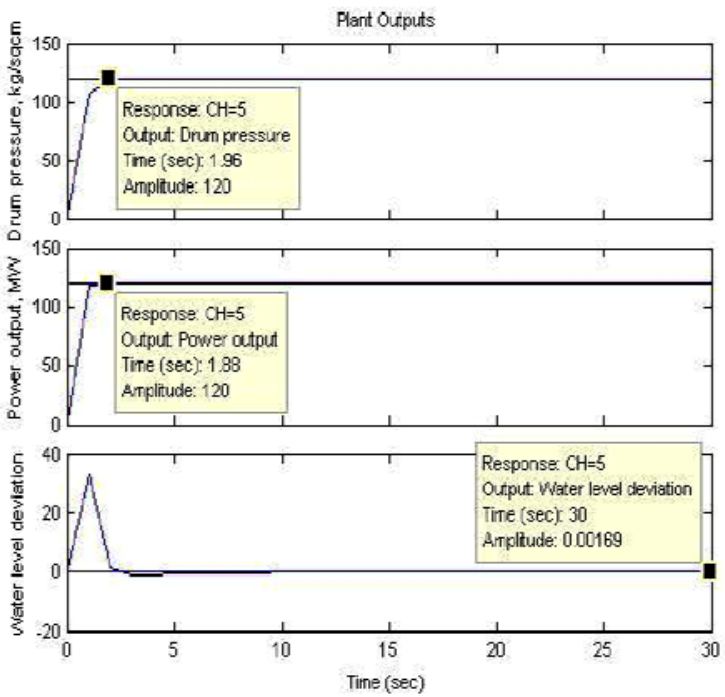

Figure 4. Set point responses with control horizon $(\mathrm{CH})$ value of 5

Figure 3 and 4 clearly indicate that settling time of responses is very large with control horizon equal to 1 hence set point tracking is worst in this case but the peak overshoot in water level response is least. The responses are almost similar with control horizon value of 2 and 5.

\section{SIGNIFICANCE OF CONTROL HORIZON TO PREDICTION HORIZON RATIO}

The figure 5 shows the controller response with control horizon value of 2 and prediction horizon value of 4 i.e control to prediction horizon ratio $(\mathrm{M} / \mathrm{P})=0.5$

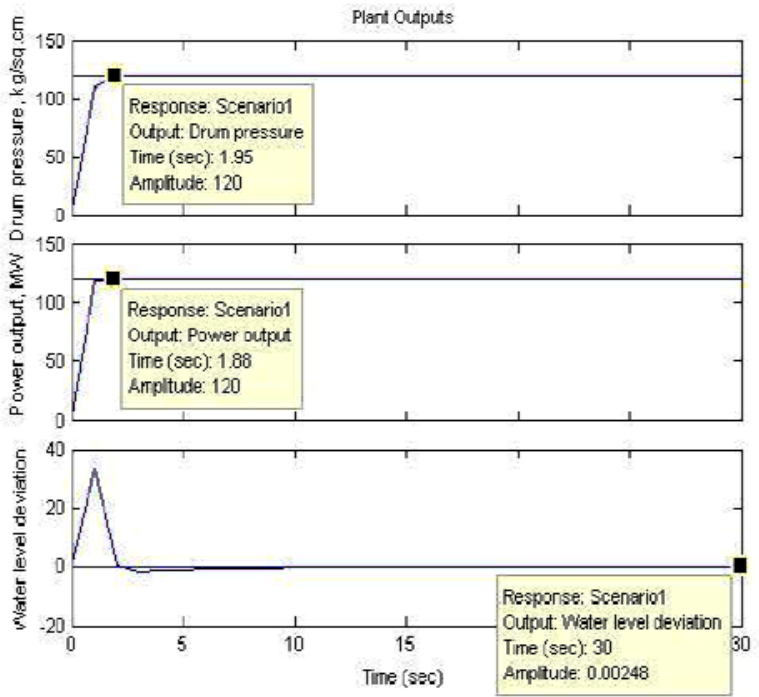

Figure 5. Set point responses with $\mathrm{M} / \mathrm{P}=0.5$

Now the comparison of figure 4 and figure 5 reveals that the same value of $M / P$ ratio results in identical set point tracking response. 


\section{EFFECT OF VARIATION IN RATE WEIGHT ON MANIPULATED VARIABLE MOVES}

The figure 6 presents the comparision of calculated moves in the three manipulated variables with input rate weight of 0.1 and 0.8 .It clearly indicates that the increase in the value of input rate weight results in decrease in the required value of discrete moves in manipulated variable i.e decrease in the amount of control effort required for set point tracking.

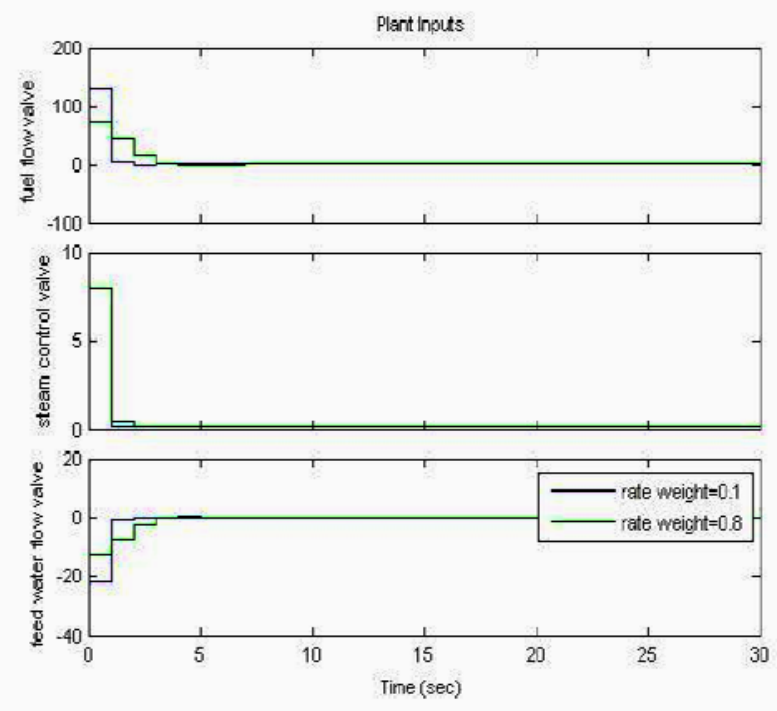

Figure 6. Manipulated variable moves with input rate weight of 0.1 and 0.8

\section{EFFECT OF VARIATION IN SAMPLING INTERVAL}

The effect of variation of the sampling interval for MPC in the setpoint tracking response is revealed in figure 7. The responses are obtained for three different values of sampling interval which are 1, 2 and 5 seconds. The setteling times of these responses for the output drum pressure are observed to be 1.38, 2.03 and 5 seconds respectively and for the output power output are $0.99,2.03$ and 5 seconds respectively, which clearly shows the degradation in performance with increase in the value of sampling interval.

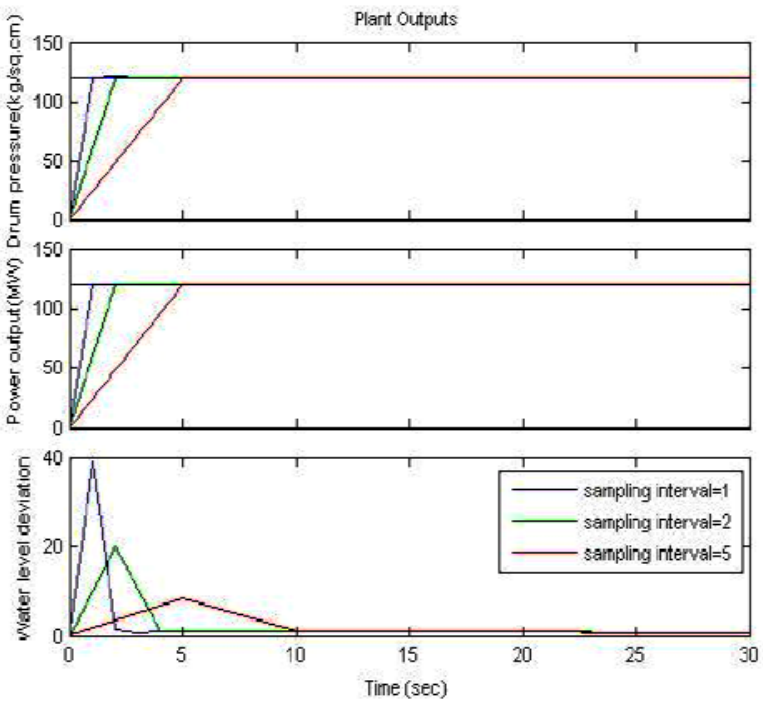

Figure 7. Set point tracking response of MPC for sampling interval of 1, 2 and 5 seconds 


\section{CONCLUSION}

It has been observed that the response of MPC controller is very fast with very small settling time and very good set point tracking performance as compared to the conventional controllers. Further it has been found that the same control horizon to prediction horizon ratio results in same controller performance and the increase in the value of input rate weight results in decrease in control moves in manipulated variables. An increase in the value of sampling interval for MPC has resulted in an increase in the setteling time of the response

\section{REFERENCES}

[1] M. Sarailoo, B. Rezaie and Z. Rahmani, "MLD Model of Boiler Turbine System based on PWA Linearization approach”, International Journal of Computer Science and Engineering, 2(4), pp. 88-92, 2012.

[2] Junxia Mu and David Rees, “Approximate Model Predictive Control for Gas Turbine Engines”, Proceeding of the 2004 American Control Conference Boston, Massachusetts, 2004.

[3] T. Rajkumar,V.M. Ramaa Priyaa and K. Gobi, "Boiler Drum Level Control by using Wide Open Control with Three Element Control System”, International Monthly Referred Journal of Research in Management and Technology, Vol. II, 2013.

[4] Rekha Rajan, Muhammed Salih P and N. Anil Kumar, "Speed Controller Design for Steam Turbine”, International Journal of Advanced Research in Electrical Electronics and Instrumentation Engineering”, Vol. 2, Issue 9, 2013.

[5] Omar Shahin, Mohammad El-Bardini and Nabila M. El-Rabaie, "Control Scheme of a Boiler Turbine using Adaptive Wavelet Neural Network”, Journal of Engineering Sciences,Assiut University,Vol. 39, No. 6, pp. 13871401,2011 .

[6] Saeed Balochian and Soheil Vosoughi, "Design and Simulation of Turbine Speed Control System based on Adaptive Fuzzy PID Controller”, Advances in Mechanical Engineering and its Applications (AMEA), Vol. 1, No. 3, 2012.

[7] Wen Tan and Fang Fang, "Linear Analysis and Control of a Boiler Turbine Unit", Proceedings of the $17^{\text {th }}$ Word Congress the International Federation of Automatic Congress, Seoul, Korea, 2008.

[8] Pradeep Kumar Juneja, A.K. Ray, "Prediction Based Control of Lime Kiln Process in a Paper Mill”, Journal of Forest Products and Industries, 2(3), pp. 58-62, 2013.

[9] Pang-chia Chen, Jeff S. Shamma, "Gain Scheduled l'-Optimal Control for Boiler Turbine Dynamics with Actuator Saturation”, Journal of Process Control 14(3), pp. 263-277, 2004.

[10] Shaoyuan Li, Hongbo Liu, Wen-Jian Cai, Yeng-Chai Soh and Li-Hua Xie, “A New Coordinated Control Strategy for Boiler Turbine System of Coal Fired Power Plant”, IEEE Transactions on Control Systems Technology, Vol. 13, No. 6, 2005

[11] FAN liping, ZHANG Jun, HUANG Xing, HUANG Dong, “The Design of the MISO Model Predictive Controller for Bioreactor”, TELKOMNIKA Indonesian Journal of Electrical Engineering, Vol. 10, No. 6,pp. 1163-1170, 2012.

[12] Fateme Pirouzmand, "Robust Model Predictive Control based on MRAS for Satellite Attitude Control system", International Journal of Electrical and Computer Engineering, Vol. 4, No. 1, pp. 81-92, 2014.

[13] Deepa Thangarelusamn, Lakshmi Ponnusamy, "Elimination of Chattering using Fuzzy Sliding Mode Controller for Drum Boiler Turbine System”, CEAI, Vol. 15, pp. 78-85, 2013.

\section{BIOGRAPHIES OF AUTHORS}

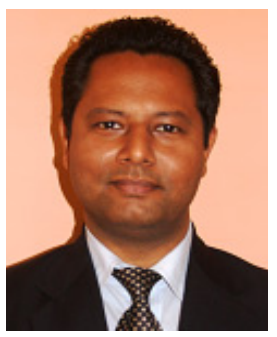

He is working as an Asst. Professor in ECE department of Graphic Era Hill University; Bhimtal Campus. He earned his M.Tech degree in Digital Communication from U.P.T.U, Lucknow and B.Tech degree in Electronics and Communication from Birla Institute of Applied Sciences, Bhimtal. He has an experience of around 12 years of teaching and administration. He is a life time member of ISTE.His areas of interest are multivariable control system, digital design and signal processing.

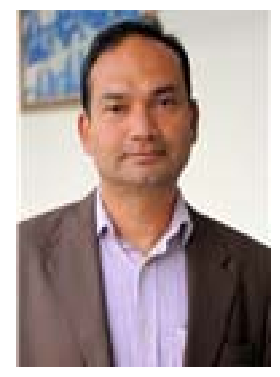

He has a Ph.D from IIT Roorkee in the area of Control Systems. He earned his M.Tech degree in Instrumentation Engineering from University Campus, DAVV, Indore and B.Tech in Electronics \& Instrumentation from Institute of Engg. And Tech., University Campus, M.J Prohilkhand University, Bareilly. He is presently working as Professor in EEE Department, GEU, Dehradun. He has 15 years of teaching and research experience. He has been the recipient of MHRD scholarship for two years at IIT Roorkee during Ph.D. and New Idea Fund scholarship at CEERI Pilani for one year during M.Tech. He is a life member of ISTE and annual member of IPPTA. His research interests include multivariable control system, prediction based control systems, modern control system, system theory, fuzzy control system and a process control. 


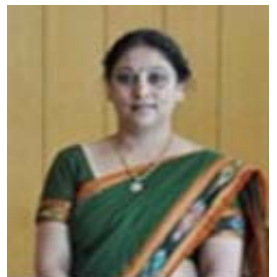

She is working as Professor in ECE department of GEU, Dehradun. She has and PhD from IIT Roorkee. She has a vast experience in the area of teaching, research and administration. She has worked as a faculty member for around 15 years and has taught several core courses like Basic Electronics, Electronic Devices and Circuits, Communication Engineering etc. as well as advanced courses like Soft Computing Fuzzy Logic Control System, Artificial Intelligence etc. 